\title{
Natural Fiber Incorporated Polymer Matrix Composites for Electronic Circuit Board Applications
}

\author{
V. S. Chandrika, ${ }^{1}$ A. Anamika, ${ }^{2}$ C. Jeeva $\left(\mathbb{D},{ }^{3}\right.$ Bhagavathi Perumal, ${ }^{4}$ S. Sanal Kumar, ${ }^{5}$ \\ J. Femila Roseline, ${ }^{6}$ and Ishwarya Komalnu Raghavan $\mathbb{D}^{7}$ \\ ${ }^{1}$ Department of Electrical and Electronics Engineering, KPR Institute of Engineering and Technology, Coimabatore 641407, \\ Tamil Nadu, India \\ ${ }^{2}$ Department of Electrical and Electronics Engineering, Galgotias College of Engineering and Technology, \\ Greater Noida 201310, India \\ ${ }^{3}$ Department of Electrical and Electronics Engineering, Sri Sairam Engineering College, Chennai 600044, Tamil Nadu, India \\ ${ }^{4}$ Department of Civil Engineering, Sri Sairam Engineering College, Chennai - 600044, Tamil Nadu, India \\ ${ }^{5}$ Department of Instrumentation, NSS College Nemmara, Palakkad, India \\ ${ }^{6}$ Department of Electronics and Communication Engineering, Saveetha School of Engineering,SIMTAS,Saveetha University, \\ Chennai, Tamil Nadu, India \\ ${ }^{7}$ Department of ElectroMechanical Engineering, Faculty of Manufacturing, Institute of Technology, Hawassa University, Ethiopia
}

Correspondence should be addressed to Ishwarya Komalnu Raghavan; ishwarya138@hu.edu.et

Received 19 September 2021; Accepted 16 December 2021; Published 29 January 2022

Academic Editor: P Ganeshan

Copyright (c) 2022 V. S. Chandrika et al. This is an open access article distributed under the Creative Commons Attribution License, which permits unrestricted use, distribution, and reproduction in any medium, provided the original work is properly cited.

\begin{abstract}
There are many more applications for fibre-reinforced epoxy composites than there are for metals and alloys today. For example, sustainable, recyclable, and biodegradable reinforcements have been used in numerous studies to improve the mechanical and thermal properties of composite materials. It was discovered that the properties of epoxy-based composites could be improved by combining biosolid waste sugarcane bagasse ash fillers, madar fibre, and epoxy resin. Conventional compression molding techniques were used to prepare the sugarcane bagasse ash (SBA) particles and madar fibre-reinforced epoxy resin-based composites (PMCs), which were loaded with varying amounts of fibre and fillers. Hybrid biocomposites were evaluated for mechanical (tensile, flexural, impact, and hardness) and water absorption characteristics. Epoxy matrix composites containing 28 wt.\% madar fibre and 7 wt.\% sugarcane bagasse ash fillers had tensile, flexural, hardness, and impact values of $61 \mathrm{MPa}, 147 \mathrm{MPa}$, and $54 \mathrm{~kJ} / \mathrm{m}^{2}$, respectively.
\end{abstract}

\section{Introduction}

In recent years, researchers all over the world have been studying to incorporate the inorganic nanoparticles or fillers into the polymer matrix. This work has attracted the increasing interest of the researchers because of the improved mechanical, thermal stability, electrical, optical, and wear resistance properties of several filler-based composites when compared with various neat polymers [1-3]. Usually, PMCs are exploited in aircraft, automotive, and electronic applications. The fabrication of printed circuit boards (PCBs) mainly based on woven glass fibre cloths and other reinforcements, including paper, glass fibre matte, nonwoven glass fibres, nonwoven aramid fibres, and other fillers, is the most widely utilized for PCB materials. Figure 1 shows the schematic illustration of PCBs. Generally, the PCB base materials come in various shapes and sizes. They all contain resin systems, reinforcements, and conductors. Epoxy, cyanate ester, polyimide, polyester, and polytetrafluoroethylene are among the resins used.

A variety of technical applications have proven that natural fillers and fiber-reinforced thermoplastic composites 


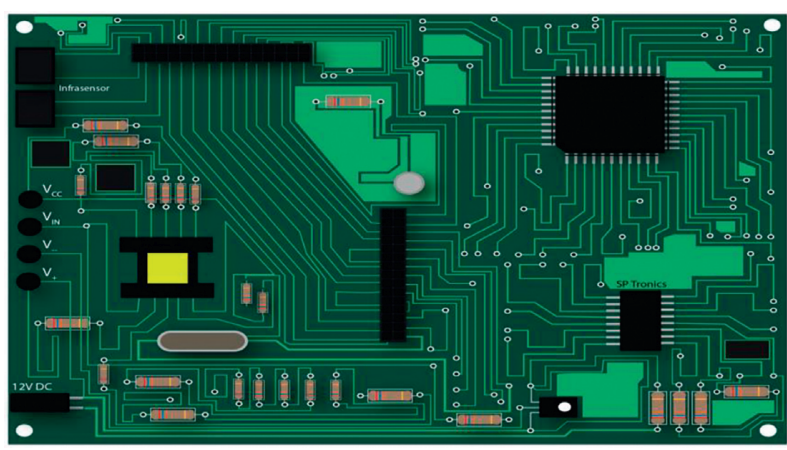

FIgURE 1: Printed circuit board schematic diagram.

have excellent properties. Due to their low density, good thermal insulation, mechanical properties, reduced tool wear, unlimited availability, low cost, and hassle-free disposal, thermoplastic fibres such as aramid and glass are increasingly used as thermoplastic reinforcement materials. The strength and cost of wood fibre/particle cannot be matched with synthetic or mineral-filled thermoplastics. Artificial and mineral fibres cause more wear on processing equipment than wood filler does. Wood reduces fibre damage during processing, allowing for the recycling of production waste without compromising quality. Available, renewable, and low density make them an attractive ecoalternative to current composite materials made of glass, carbon, and man-made fibres. They are also mechanically sound. Due to their environmental friendliness, natural fibre composites are used in transportation, military, construction, packaging, consumer products, etc. [4]. Most of the research studies have focused on the naturally available fillers such as sawdust, rice husk, coconut shell powder, sugarcane bagasse ash, eggshell powder, wood flour, fly ash, and red mud because of their cost-effectiveness and abundance. Carbon nanotubes, nanoclay, silicon carbide, talc, and calcium carbonate are some of the inorganic fillers that are mostly or widely used reinforcements for polymer matrices. For a variety of rubber applications, fillers have also been used to improve the properties of various composites $[5,6]$. The tensile strength of biocomposites decreases slightly as the filler content increases, but their strength remains adequate. Increased filler loading resulted in lower composite tensile strengths and Izod impact strengths due to poor interfacial bonding between the matrix polymer and filler [7]. Study of nonwood and kenaf natural fibres with high stiffness and strength values was conducted [8]. A higher aspect ratio makes them an ideal material for the fibrous phase, according to their research. Additional measurements are required to interpret the mechanical properties of a composite system when its relative volume, properties, or fabrication process changes. As a result, experiments may take a long time and be expensive. Moisture absorption increased as fibre loading increased, according to findings [9]. The pineapple leaf fibre reinforced with a lowdensity polyethylene matrix was being studied for its moisture absorption properties at the same time, he explained. With fibre loading, moisture absorption increases almost linearly. George et al. [10] studied a number of polymers and concluded that when submerged in water, their composites absorbed moisture from the humid atmosphere. Composites with natural fibres have a lower mechanical strength because they absorb more moisture than synthetic fibres. It is stated in [11] that "Composite material with a $45 \mathrm{wt} \%$ fibre content and $5 \mathrm{~mm}$ fibre length performs optimally". A study of banana fibre-reinforced composites using a variety of banana fibre lengths and banana fibre weight percentages was conducted by Athijayamani et al. [12]. Composites with banana fibre lengths of 30 to $40 \mathrm{~mm}$ and banana fibre content of $40 \mathrm{wt}$ percent exhibited the best mechanical properties. For example, polyester resin composites reinforced with Sansevieria cylindrica fibres were proposed [13]. Researchers studied storage modulus, damping factor, and loss modulus of biodegradable Sansevieria cylindrica fibre-reinforced polyester matrix composites. There was a significant effect on properties due to changes in fibre length, content, and chemical treatment under transient temperatures. Basalt fibres and their adhesion to polypropylene matrix were investigated in a study by Sreenivasan et al. [14]. Maleic anhydride grafted PP was also used to achieve different fibre lengths and matrix modification. Experimentally determined basalt fibre mechanical properties by tensile tests on a single filament of basalt were studied. Study of mechanical properties, including tensile strength and flexural strength, of composite materials with 20 percent fibre content in HDPE was conducted. Polymers are reinforced with fibres derived from natural sources, such as animal fibres [15]. Epoxy resin is the most common structural adhesive and engineering adhesive used in human life applications, and it has a high bonding strength. An epoxy resin matrix with madar fibre reinforcement and sugarcane bagasse ash filler is used in the present work to fabricate a composite. In a hand layup technique, different weight fractions of fibre and filler were used. Impact, hardness, and water absorption were among the other properties tested on the composites, in addition to tensile and flexural strength [16-18]. This study examined the effects of adding sugarcane bagasse ash particles to a madar fibre/epoxy resin matrix on various mechanical properties.

\section{Materials and Methods}

The Apocynaceae family produces the madar fibre. Fibres are extracted from the madar plant's stem. An abundance of madar fibre (MF) is found in the agricultural lands of the southern region of India. Figure 2 shows the madar plant. Madar fibre contains mucilaginous substances in the primary wall, while cell lumen is found in the secondary wall. This is due to the fact that it contains more lignin than existing bast fibres. We can use it in lightweight applications such as textiles and automobiles because of its lower density. A natural bast fibre with lower elongation, higher strength, and better tensile property is known as MF. Fibres such as glass and carbon can be substituted for it in polymer matrices. In this current work, six different biocomposites were produced by using the biowastes, i.e., madar fibre, sugarcane bagasse ash filler, and epoxy resin through the conventional 


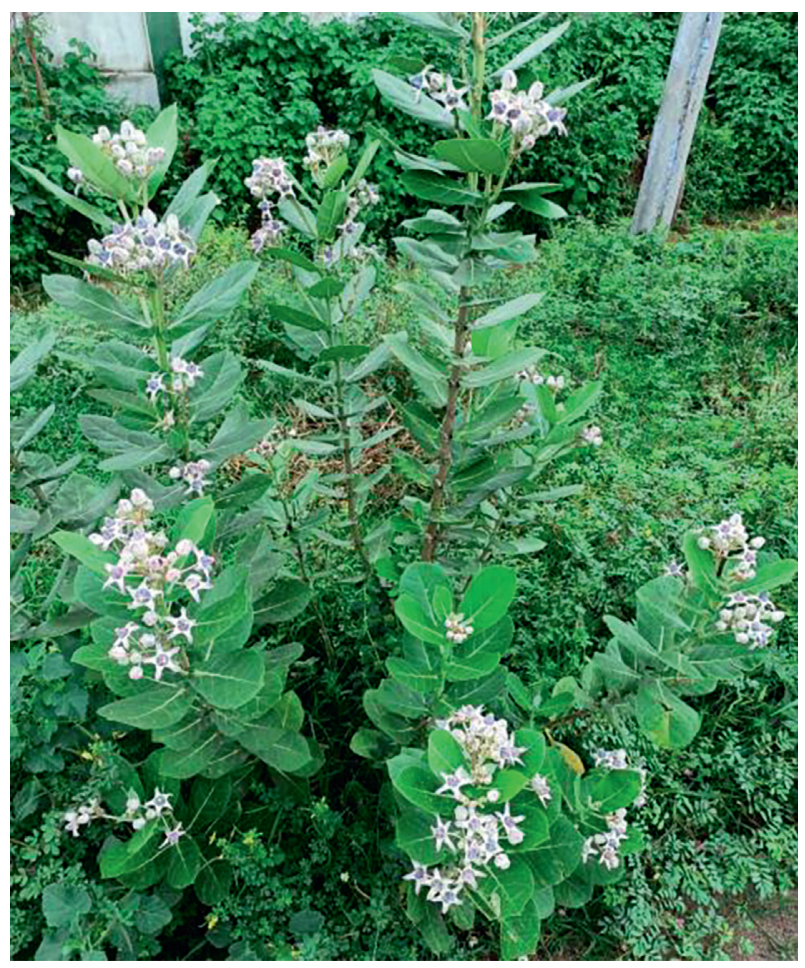

Figure 2: Madar plant.

compression molding technique. Compression molding is a composite manufacturing approach generally utilized to make high-volume composite components, such as automobile components. Cold compression and hot compression moldings are the two compression molding processes. Figure 3 shows the schematic image of the compression molding technique.

Different percentages of fibre $(35,34,32,30,28$, and 26 wt. \%) and filler loadings (0, 1, 3, 57 , and 9 wt. \%) with a mould of dimension of about $250 \mathrm{~mm}$ long, $250 \mathrm{~mm}$ width, and $5 \mathrm{~mm}$ thick were used for the fabrication of specimens. The cavity surface of the mould was waxed in order to facilitate the removal of the composite plate. It was then mixed for 45 minutes with measured vinyl ester resin to achieve homogeneity and reduce air bubble generation. The supplier also recommended adding 1.5 percent dimethylaniline accelerator, 1.5 percent methyl ethyl ketone peroxide catalyst, and 1.5 percent cobalt naphthenate promoter to the mixture. Once the mould cavity was completely filled, a die was used to seal it. In order to cure properly, it is compressed for 30 hours at room temperature with a constant pressure of $125 \mathrm{kPa}$. They were then removed from the mould cavity. A similar procedure has been adopted to prepare the other five biocomposite plate preparations with different percentages of fibre and filler loadings.

2.1. Mechanical Testing. A saw cutter was used to cut the fabricated composite plates to the desired shapes for different test specimens. Using a UTM, tensile and flexural tests were performed at room temperature. For each weight percentage, three specimens were tested to ensure that the results could be repeated. The ASTM D638 standard specifies a crosshead speed of two millimetres per second $(\mathrm{mm} /$ sec) for testing tensile strength. The ASTM D790-10 standard was followed, and the crosshead speed was set at $2 \mathrm{~mm} /$ sec. When a reinforced epoxy resin composite is able to absorb energy from an impact load without breaking, it is said to have impact resistance. The interfacial adhesions between the filler and matrix, the presence of voids, the filler's influence, and the testing environment all have an impact on the impact strength of a composite. The Charpy test method evaluated impact strength according to ASTM D256. Also, the hardness was measured using the Barcol Hardness tester, according to the ASTM 2583 standard.

2.2. Water Absorption Behaviour. This was performed in accordance with the ASTM D570-99 standard. Initially, they were baked at $80^{\circ} \mathrm{C}$ until they reached a uniform weight. Five replicas of each specimen were immersed in normal water for 48 hours. A known weight $\left(W_{1}\right)$ of each specimen was immersed in water for 48 hours one after the other. Moisture on the specimen surface was removed with absorbent paper afterward. Immediately, the weight of the specimen was measured. The water absorption percentage was determined by finding the weight difference between the dry specimens and specimens immersed in water by the following equation:

$$
\text { percentage of water absorption }=\left(\frac{W_{2}-W_{1}}{W_{1}}\right),
$$

where $W_{2}$ is the weight of the specimen after test and $W_{1}$ is the weight of the specimen before test.

\section{Results and Discussions}

3.1. Tensile Strength. In order to determine the tensile strength of biocomposites, different percentages of fibre and filler were used in the fabrication process. Figure 4 shows the tensile strength results as a function of fibre and filler loading weight percentages for biocomposites.

The ultimate tensile strengths of $0,1,3,5,7$, and $9 \mathrm{wt} . \%$ of sugarcane bagasse ash-filled composites were in the range of $34,39,45,52,61$, and $41 \mathrm{MPa}$, respectively. According to the researchers, 7 wt. \% filler improved tensile strength by 44 percent over pure epoxy resin/madar fibre-reinforced composite specimens. After increasing it from zero to seven weight percent, the tensile strength increased dramatically from $34 \mathrm{MPa}$ to $61 \mathrm{MPa}$. Tensile strength improved by 44 percent when filler weights of 7 weight percent were added to epoxy resin/madar fibre-reinforced composite specimens. The tensile strength dropped suddenly from 61 to $41 \mathrm{MPa}$ at 9 percent filler weight. This was due to the filler and a matrix having distorted bonding properties, as well as the presence of voids. Increase in biocomposite tensile strength of 34 to $61 \mathrm{MPa}$ was observed with variations in filler weight percentage. $61 \mathrm{MPa}$ tensile strength was achieved by the biocomposite at $7 \%$ weight. As a result of this, it was 44.26 percent higher than that of the pure epoxy resin/madar fibre-reinforced composite samples. Figure 5 depicts the tensile stress-strain curves for various filler weight 

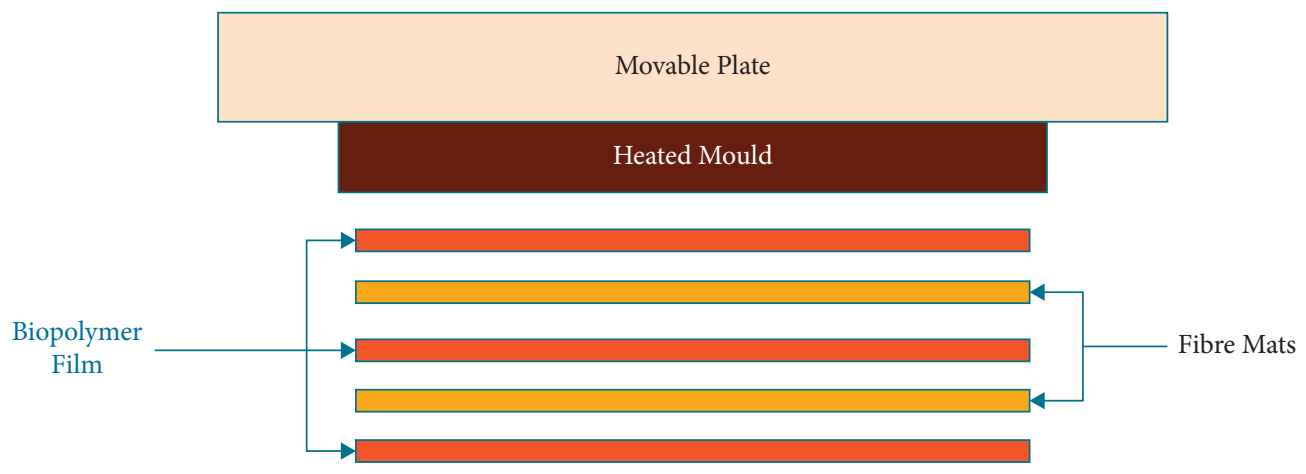

Heated Mould

Fixed Plate

FIGURE 3: Schematic image of the compression molding technique.

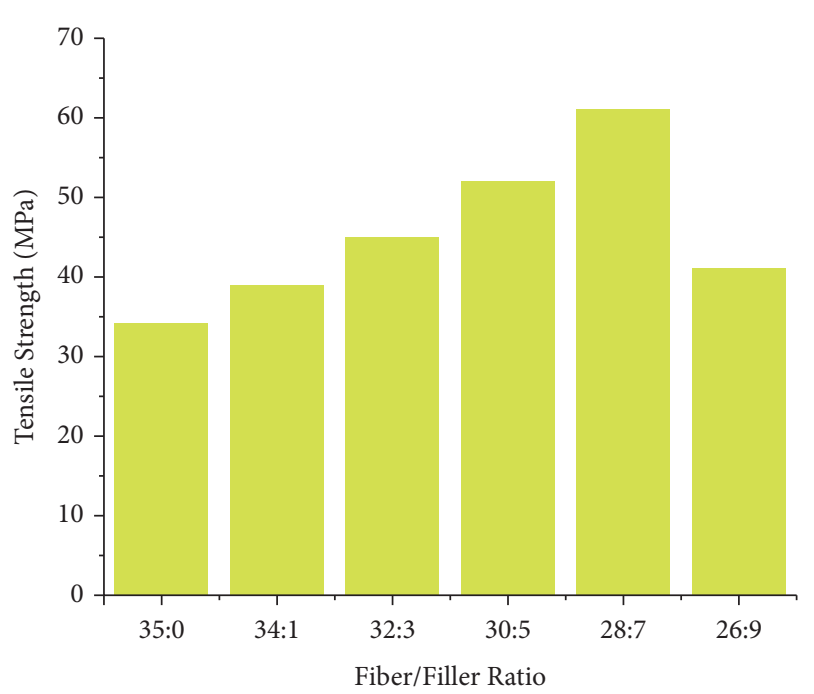

FIgURE 4: Epoxy resin/madar fibre/sugarcane bagasse ash composites: effect of fibre/filler loading on tensile strength.

percentages. Moreover, biocomposites showed an increasing trend in the fibre and filler weight percentage up to 28 wt. $\%$ and 7 wt. $\%$.

Fiber and filler reinforcement carried the tensile load more effectively than the matrix, which caused the matrix to break. It has higher stiffness and strength. Hence, it was observed that when fibre and filler weight percentage was increased beyond $28 \mathrm{wt}$. $\%$ and $7 \mathrm{wt}$. \%, the strength of biocomposites decreased. The increase in filler weight percentage continued in a sinusoidal pattern. It has been found that the epoxy matrix and filler do not adhere well to each other when the filler percentage is high enough. While being tested for tensile strength, the material developed holes and showed reduced strength.

Figure 6 depicts the tensile load-displacement curves for the various fibre and filler weight percentages. The percentage of elongation between $0 \mathrm{wt}$. \% and $9 \mathrm{wt}$. \% ranged from 1.25 to $3.4 \%$, correspondingly.

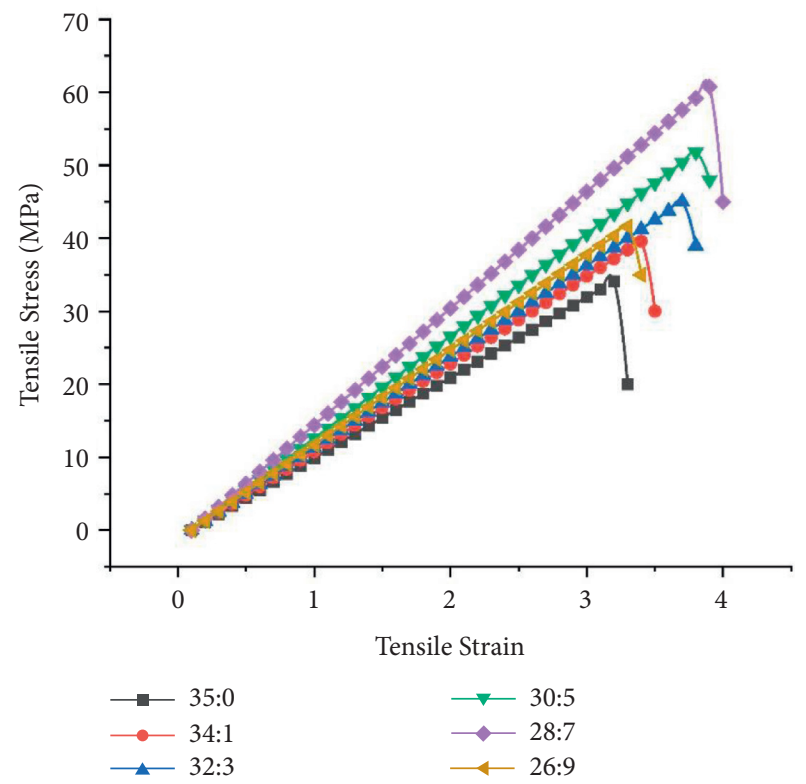

Figure 5: Tensile strain vs. tensile stress curves for epoxy resin/ madar fibre/sugarcane bagasse ash composites.

An elastic material's tensile modulus is a measure of stiffness. The effect of different weight percentage addition of the filler material into the fibre and epoxy resin combination is illustrated in Figure 7.

Moreover, the addition of filler weight from $0 \mathrm{wt} \%$ to $9 \mathrm{wt} \%$ increased or enhanced the modulus value from $1.4 \mathrm{GPa}$ to $2.6 \mathrm{GPa}$. Optimum tensile strength of $61 \mathrm{MPa}$ of sugarcane bagasse ash filler/madar fibre/epoxy resin composites was close to that of coconut shell powder-reinforced epoxy, oil palm shell powder-reinforced polyester, oil palm shell powder and kenaf-coconut-kenaf fibre-reinforced polyester composites. Composites made from groundnut powder and vinyl ester reinforcement were tested at 27.3 MPa, tamarind seed filler composites were tested at 33.21 MPa, and composites made from date palm wood flour 


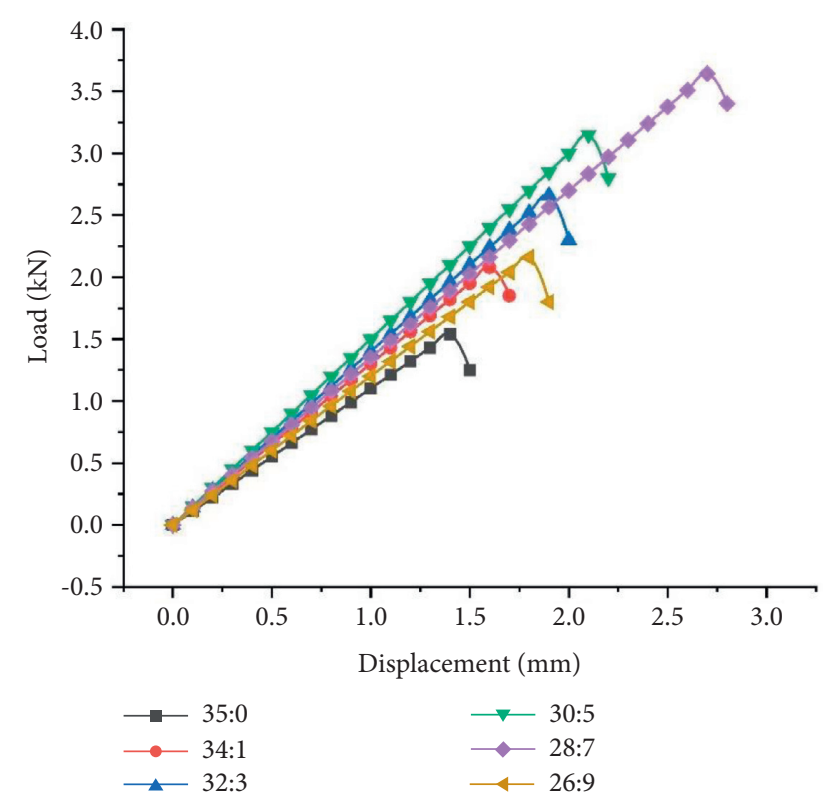

Figure 6: Displacement vs. load curves for epoxy resin/madar fibre/sugarcane bagasse ash composites.

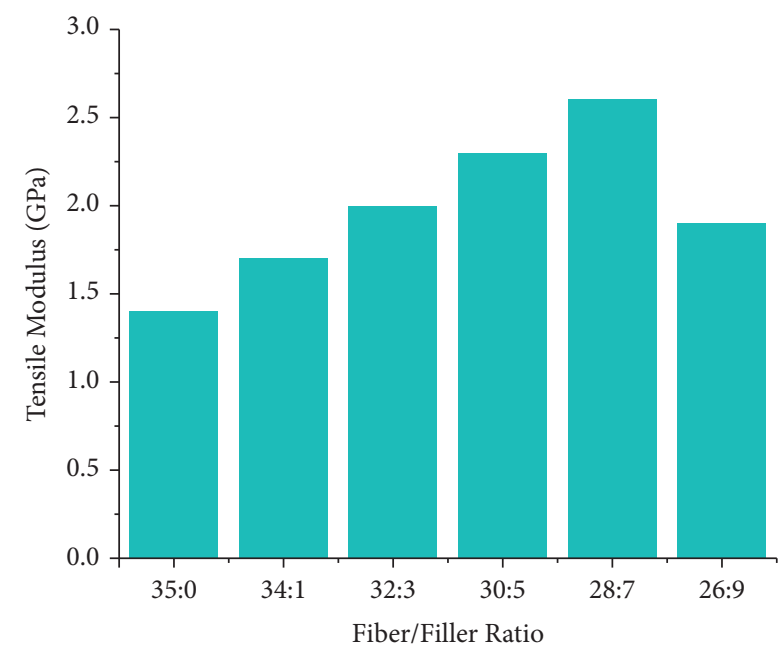

FIGURE 7: Effect of fibre/filler loading on tensile modulus for epoxy resin/madar fibre/sugarcane bagasse ash composites.

and glass fibre-reinforced polypropylene were tested at 24.89 MPa. Composites made from boiled eggshell powder and vinyl ester reinforcement were tested at $23.6 \mathrm{MPa}[6,12,13]$. This comparative analysis on mechanical behavior (tensile and other properties) of the sugarcane bagasse ash filler/madar fibre/epoxy resin composite shows that the sugarcane bagasse ash filler/ madar fibre/epoxy resin is a promising material for engineering structures.

3.2. Flexural Strength. Figure 8 shows the bending test results obtained on variations in the flexural characteristics obtained for the sugarcane bagasse ash/madar fibre/epoxy resin composites with the effect of fibre/filler loadings.

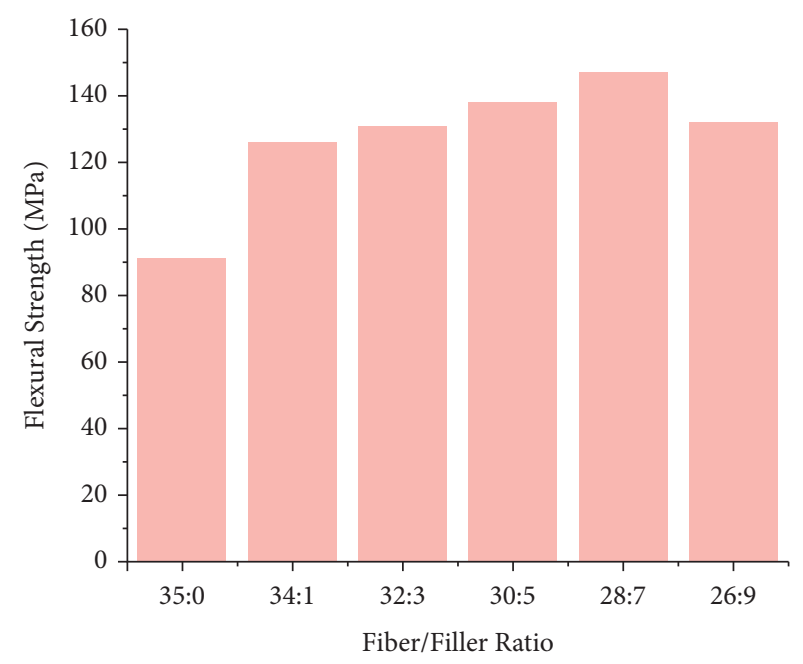

FIgURE 8: Epoxy resin/madar fibre/sugarcane bagasse ash composites: effect of fibre/filler loading on flexural strength.

The flexural strength and flexural modulus of the epoxy resin/madar fibre composite specimen were $91 \mathrm{MPa}$ and $5.8 \mathrm{GPa}$, respectively. Figure 9 shows the variation of flexural modulus for all composites. The flexural strength of the composites increased with filler loadings of $1,3,5$, and 7 wt.\% when compared to pure epoxy resin/madar fibre specimens. Also, the flexural modulus increased as the sugarcane bagasse ash filler content increased. Comparing sugarcane bagasse ash/madar fibre/epoxy resin composite specimens with pure epoxy resin/madar fibre composite specimens, the average flexural strength increased as the filler loading increased. Composites with sugarcane bagasse ash/madar fibre loadings of 28 and 7 weight percent, respectively, showed increased flexural strength of 38 and 57 percent over pure epoxy resin/madar fibre composite specimens. Then, a decreased trend was evident from the test results obtained beyond the $7 \mathrm{wt}$. \% filler loadings. The flexural modulus remained almost constant with the sugarcane bagasse ash/epoxy resin/madar fibre composite specimen composites manufactured with filler loading of 1 and 3 wt. \%. Sugarcane bagasse ash loading of 7 wt. \% increased flexural strength dramatically. When the filler was omitted, the flexural strength was 38 percent higher than that of pure resin/madar fibre composites.

Sugarcane bagasse ash/madar fibre-reinforced composites with a 7 weight percent sugarcane bagasse ash content had a flexural strength of $147 \mathrm{MPa}$, which was 38 percent higher than that of pure resin/madar fibre-reinforced composites. Admittedly, the flexural modulus was observed to be highest for $7 \mathrm{wt}$. \% filler loading. There was a sinusoidal decrease in flexural strength with filler loadings higher than $7 \mathrm{wt}$. \%, due to the agglomeration and incompatibility between a higher quantity of sugarcane bagasse ash filler and epoxy resin. Furthermore, it can be significantly observed that the trend of the flexural strength of sugarcane bagasse ash/madar fibre-reinforced composites was similar to the tensile strength for various filler loadings. As shown in Figure 10, sugarcane bagasse ash/madar fibre/epoxy resin 


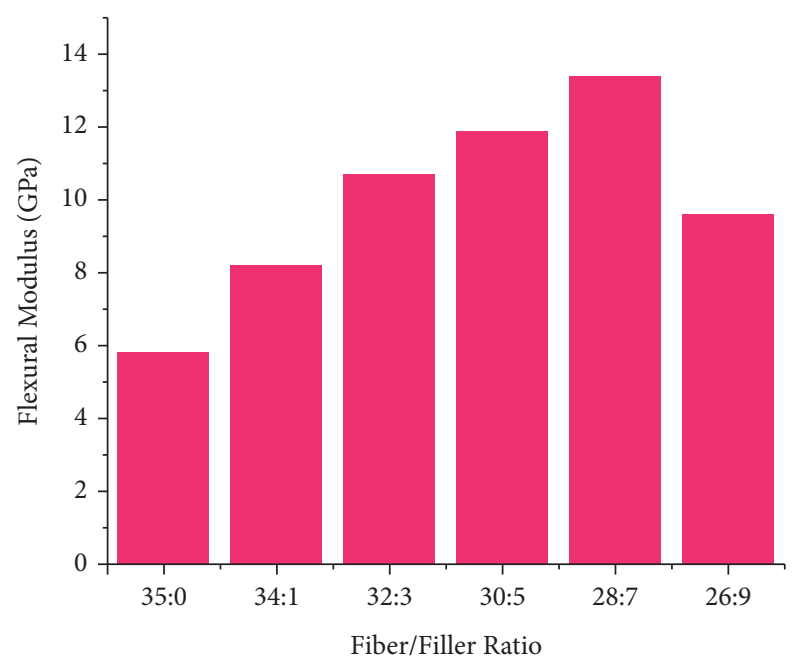

FIGURE 9: Equivalent flexural modulus of epoxy resin/madar fibre and sugarcane bagasse ash composites with different percentages of fibre/filler loadings.

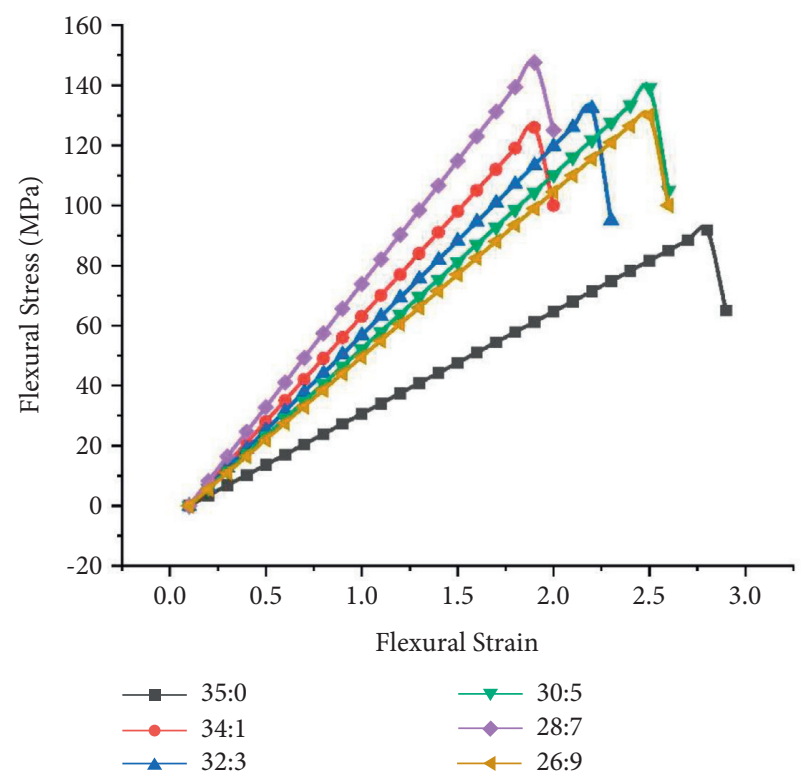

Figure 10: Flexural strain vs. flexural stress curves for epoxy resin/ madar fibre/sugarcane bagasse ash composites.

composites with varying filler loadings exhibit different flexural stress and strain curves.

$147 \mathrm{MPa}$ was the maximum flexural strength of the sugarcane bagasse ash and madar fibre-reinforced epoxy resin composites, compared to $122 \mathrm{MPa}$ for tamarind seed filler/vinyl ester composites, $91 \mathrm{MPa}$ for Arundo donax fillers/epoxy composites, and $82 \mathrm{MPa}$ for wood apple shell/ epoxy composites.

3.3. Impact Strength. Unnotched sugarcane bagasse ash/ madar fibre/epoxy resin composites were held in an Izod Charpy instrument and broken by a pendulum. It is shown in Figure 11 that the composites with different filler loadings had different average impact energy values. Experimentally, sugarcane bagasse ash-madar fiber-epoxy resin composites showed increased impact strength with increase in filler loading. When filler content was increased by 7 weight percent, impact energy increased by 22.28 percent. Importantly, the sugarcane bagasse ash/madar fibre/epoxy resin composites exhibited a maximum impact strength of $17.5 \mathrm{~kJ} / \mathrm{m}^{2}$ at $7 \mathrm{wt}$ \% of filler loading, and it was $22.28 \%$ higher than the madar fibre/epoxy resin composites. When compared with neat madar fibre/epoxy resin composites, the sugarcane bagasse ash/madar fibre/epoxy resin composites were capable of absorbing high energy to stop crack propagation.

The higher impact strength of sugarcane bagasse ash/ madar fibre/epoxy resin composites was due to the filler's excellent homogeneous dispersion in the matrix, which produced excellent interfacial adhesion. Impact strength was decreased as a result of crack prevention and easy energy absorption. On the other hand, poor dispersion of filler increased the tendency to agglomerate the particle, thus minimizing their surface areas. Therefore, the crack propagation was increased, and the energy absorption was also less. The phenomenon has explained the decrease in impact strength of $9 \%$ weight loadings of the composites. Filler loading up to $7 \mathrm{wt}$. \% increased impact strength more pronouncedly.

3.4. Barcol Hardness. Figure 12 depicts the Barcol hardness values of the sugarcane bagasse ash/madar fibre/epoxy resin composites with respect to different filler loadings. It was inferred that the sugarcane bagasse ash filler was well dispersed all over the matrix and produced an excellent surface roughness. Up to $7 \mathrm{wt}$. \% increase in filler loading resulted in an increase in hardness. It had a hardness of 32. In particular, the hardness for $7 \mathrm{wt}$. \% addition of sugarcane bagasse ash increased by 41 percentage than that of the madar fibre/ epoxy resin composites. A similar trend of results was followed by many researchers, as reported on rice husk reinforced with polyester and epoxy.

Admittedly, increasing values of hardness property were produced by increasing the filler loadings, especially between $0 \%$ (neat epoxy resin with no filler) and 7 wt. \%.

3.5. Water Absorption Behaviour. Figure 13 shows the percentage of water absorption curves for the sugarcane bagasse ash/madar fibre/epoxy resin composites with average data of three specimens of different filler loadings after immersing the composite specimens in normal water. The hydrophilic nature of the filler material led to an increase in the water absorption percentage. A similar trend was observed in different natural filler/fibre-reinforced composites. Hydrophobicity of epoxy resin prevented water absorption in the four environments mentioned above.

Due to the presence of microvoids in composites, sugarcane bagasse ash/madar fibre/epoxy resin composites absorbed more water than the other five fibre/ filler combinations. With higher filler loadings, the sugarcane bagasse ash/madar fibre/epoxy resin composites contained less matrix, which resulted in an 


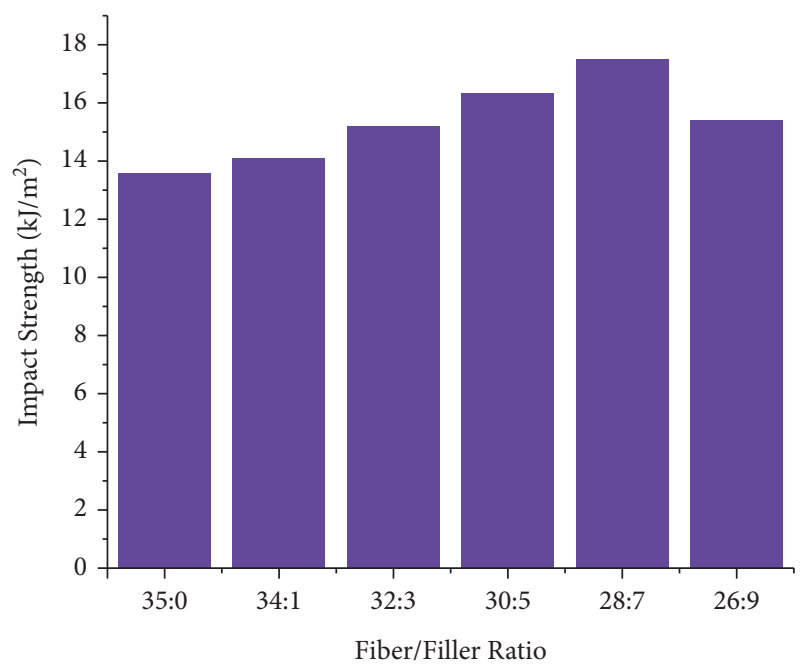

FiguRE 11: Effect of fibre/filler loading on impact strength for epoxy resin/madar fibre/sugarcane bagasse ash composites.

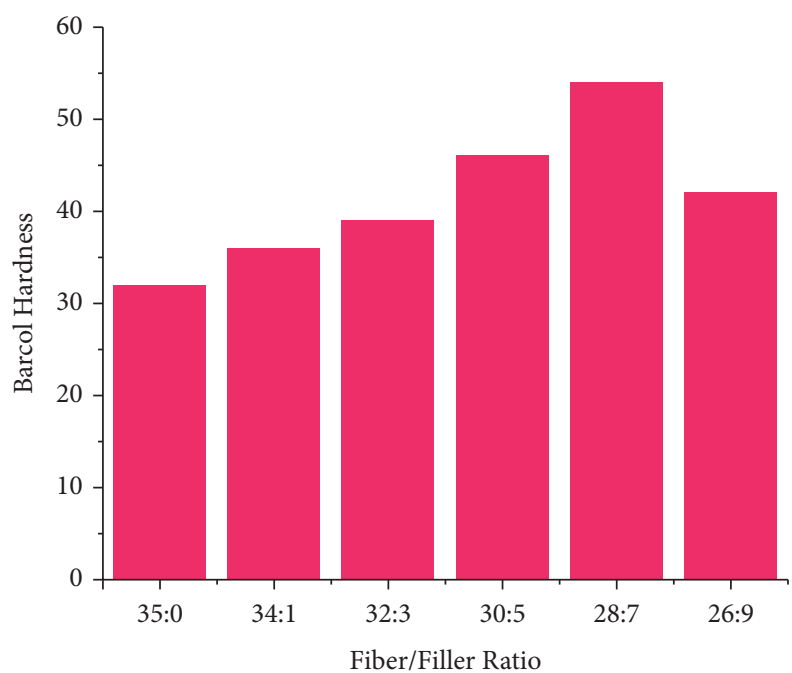

Figure 12: Effect of fibre/filler loading on Barcol hardness for epoxy resin/madar fibre/sugarcane bagasse ash composites.

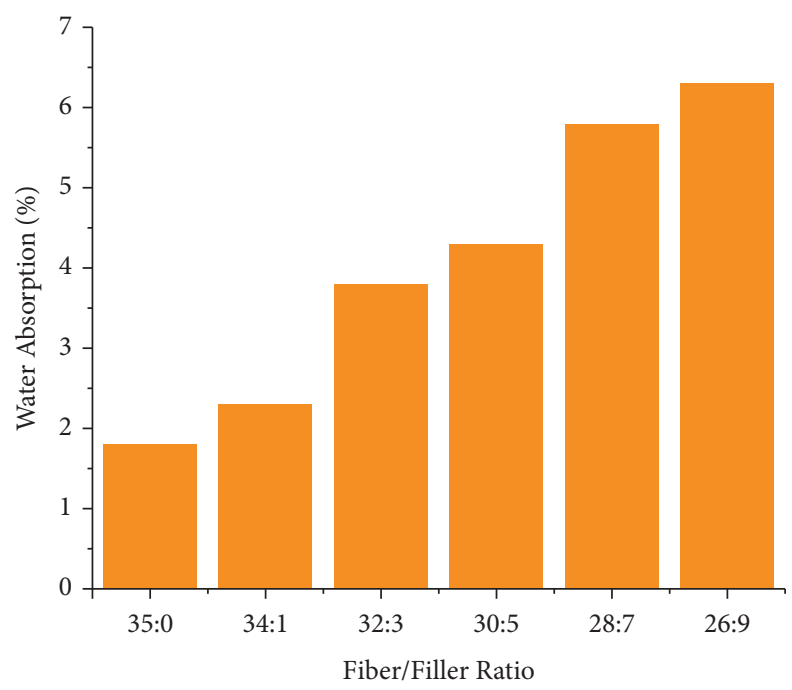

FIGURE 13: Variation of water absorption properties for epoxy resin/madar fibre/sugarcane bagasse ash composites. 
increase in voids. However, the lowest water absorption was recorded with pure epoxy resin/madar fibre when compared with the other five combinations because of the absence of sugarcane bagasse ash molecules in the particular composite specimens. The slow penetration of large molecules into the composites produced a smallest moisture absorption percentage.

\section{Conclusions}

Efforts have been made to determine how filler loading affects the mechanical and thermal properties of date palm seed-reinforced vinyl ester composites. The following conclusions are drawn from this study's promising results:

(i) In terms of mechanical and water absorption properties, the fibre/filler weight percentages of epoxy resin/madar fibre/sugarcane bagasse ash composites were found to be critical, with 28 and 7 percent being optimal.

(ii) $61 \mathrm{MPa}$ and $2.6 \mathrm{GPa}$ were the maximum tensile and modulus values for epoxy resin/madar fibre/SBA composites.

(iii) In addition, the flexural and impact tests performed on the epoxy resin/madar fibre/sugarcane bagasse ash composites with a filler loading of $7 \mathrm{wt}$. \% exhibited a maximum strength of $147 \mathrm{MPa}$ and $17.5 \mathrm{~kJ} / \mathrm{m}^{2}$, respectively. The Barcol hardness of the epoxy resin/madar fibre composites was 32 , and the addition of sugarcane bagasse ash loading of $7 \mathrm{wt}$. \% increased it by $41 \%$ than that of the epoxy resin/ madar fibre composites.

(iv) Furthermore, the water absorption test showed that the lowest and highest percentages of water absorptions were recorded in $0 \mathrm{wt} \%$ and $9 \mathrm{wt}$. \% of sugarcane bagasse ash filler weight percentage, respectively. Also, as filler loadings increased, so did the percentages of water absorption.

(v) Epoxy resin/madar fibre/sugarcane bagasse ash composites with a $7 \mathrm{wt}$. \% filler content had significantly higher tensile, flexural, impact, and hardness values compared to epoxy resin/madar fibre composites.

\section{Data Availability}

The data used to support the findings of this study are included within the article. Further data or information is available from the corresponding author upon request.

\section{Conflicts of Interest}

The authors declare that there are no conflicts of interest regarding the publication of this article.

\section{References}

[1] H. Alamri and I. M. Low, "Effect of water absorption on the mechanical properties of nano-filler reinforced epoxy nanocompositesfiller reinforced epoxy nanocomposites," Materials \& Design, vol. 42, pp. 214-222, 2012.

[2] T. Raja, V. Mohanavel, T. Sathish et al., "Thermal and flame retardant behavior of neem and banyan fibers when reinforced with a bran particulate epoxy hybrid composite," Polymers, vol. 13, no. 22, p. 3859, 2021.

[3] H. Essabir, E. Hilali, A. Elgharad et al., "Mechanical and thermal properties of bio-composites based on polypropylene reinforced with Nut-shells of Argan particles," Materials \& Design, vol. 49, pp. 442-448, 2013.

[4] V. Mohanavel, S. Suresh Kumar, J. Vairamuthu, P. Ganeshan, and B. NagarajaGanesh, "Influence of stacking sequence and fiber content on the mechanical properties of natural and synthetic fibers reinforced penta-layered hybrid composites," Journal of Natural Fibers, vol. 2021, Article ID 1875368, 13 pages, 2021.

[5] V. Mohanavel, T. Raja, A. Yadav, M. Ravichandran, and J. Winczek, "Evaluation of mechanical and thermal properties of jute and ramie reinforced epoxy-based hybrid composites," Journal of Natural Fibers, vol. 2021, Article ID 1958432, 11 pages, 2021.

[6] P. Vimalanathan, N. Venkateshwaran, and V. Santhanam, "Mechanical, dynamic mechanical, and thermal analysis ofShorea robusta-dispersed polyester composite," International Journal of Polymer Analysis and Characterization, vol. 21, no. 4, pp. 314-326, 2016.

[7] H. Ismail, N. Othman, and M. Komethi, "Curing characteristics and mechanical properties of rattan-powder-filled natural rubber composites as a function of filler loading and silane coupling agentfilled natural rubber composites as a function of filler loading and silane coupling agent," Journal of Applied Polymer Science, vol. 123, no. 5, pp. 2805-2811, 2012.

[8] Han-Seung Yang, H.-joong Kim, H.-J. Park, Bum-Jae Lee, and T.-S. Hwang, "Water absorption behavior and mechanical properties of lignocellulosic filler-polyolefi bio-composites," Elsevier, composite structures, vol. 72, pp. 429-437, 2006.

[9] A. R. Sanadi, D. F. Caulfield, R. E. Jacobson, and R. M. Rowell, "Renewable agricultural fibers as reinforcing fillers in plastics: mechanical properties of kenaf fiber-polypropylene composites," Industrial \& Engineering Chemistry Research, vol. 34, no. 5, pp. 1889-1896, 1995.

[10] J. George, S. S. Bhagawan, and S. Thomas, "Effects of environment on the properties of low-density polyethylene composites reinforced with pineapple-leaf fibre," Composites Science and Technology, vol. 58, no. 9, pp. 1471-1485, 1998.

[11] T. A. Collings, "Moisture absorption fickian diffusion kinetics and moisture profiles," Handbook of Polymer Fiber Composites, Longman Scientific and Technical, Essex, UK, 1994.

[12] M. T. Athijayamani, S. S. Winowlin, and A. Alavudeen, "Effect of fiber content on mechanical properties of short roselle and sisal fiber hybrid polyester composite," International Journal of Computer Aided Engineering and Technology, vol. 1, pp. 58-62, 2008.

[13] L. A. Pothan, S. Thomas, and N. R. Neelakantan, "Short banana fiber reinforced polyester composites: mechanical, failure and aging characteristics," Journal of Reinforced Plastics and Composites, vol. 16, no. 8, pp. 744-765, 1997.

[14] V. S. Sreenivasan, N. Rajini, A. Alavudeen, and V. Arumugaprabu, "Dynamic mechanical and thermogravimetric analysis of Sansevieria cylindrica/polyester composite: effect of fiber length, fiber loading and chemical treatment," Composites Part B: Engineering, vol. 69, pp. 76-86, 2015. 
[15] G. Antonio, M. Alfonso, C. Giovanni, and C. Flavio, "Mechanical properties of basalt Fibers and their adhesion to polypropylene matrices," Comp Part B, vol. 67, pp. 233-238, 2014.

[16] P. J. Herrera-Franco and A. Valadez Gonzalez, "A study of the mechanical properties of short natural-fiber reinforced composites," Composites Part B, vol. 36, pp. 597-608, 2007.

[17] V. Yamunadevi, K. Palaniradja, A. Thiagarajan, P. Ganeshan, and K. Raja, "Characterization and dynamic mechanical analysis of woven roven glass fiber/cerium-zirconium oxide epoxy nanocomposite materials," Materials Research Express, vol. 6, no. 9, Article ID 095057, 2019.

[18] B. N. Ganesh and B. Rekha, "A comparative study on tensile behaviour of plant and animal fiber reinforced composites," International Journal of Innovation and Applied Studies, vol. 2, pp. 645-648, 2013. 